\title{
Evaluation of Dynamic Endurance of Back Extensors in Asymptomatic College Girls: An Observational Cross-Sectional Study
}

\author{
Krupal Modi ${ }^{1}$, Mansi Ray ${ }^{2}$ \\ ${ }^{1,2}$ Assistant Professor, Shree Swaminarayan Physiotherapy College, \\ Kadodara-394327, Surat, Gujarat, India \\ Corresponding Author: Krupal Modi
}

DOI: https://doi.org/10.52403/ijshr.20220110

\begin{abstract}
Background: Prolonged sitting and reading can leads to reduced activity of trunk extensors and shown to be related to provoke back pain in near future among students. Various tests are used to evaluate the strength and endurance of abdominal and back extensors muscles which helps therapist in assessment, diagnosis and prognosis. This study evaluates endurance of the trunk extensor group of muscles using Repetitive Arch Up Test (RAUT) among college going students.
\end{abstract}

Aims: The aim of this study is to check the endurance of trunk extensor group of muscles in 19-23 years old female students studying in college.

Material \& Methodology: This is a crosssectional observational study done on 30 female participants between age group of 19-23 years studying for more than 8 hours in sitting position at one physiotherapy college. Repetitive Arch Up Test (RAUT) was used to measure endurance of back extensors. Data was collected and statistical analysis was done.

Results: The collected Data showed that, the mean and SD of RAUT is $22.73 \pm 9.896$, which suggest that there was significant reduction in the endurance of lumbar spine extensors in the undergraduate physiotherapy students attending lectures for 8 hours/day, 6 days/week.

Conclusion: The present study concluds that, the trunk extensor endurance is markedly reduced in undergraduate physiotherapy students who currently do not have back pain. But if not treated can lead to risk of developing low back pain in future.
Keywords: Back muscle endurance, College students, Repetitive Arch-up test.

\section{INTRODUCTION}

The trunk muscles are physiologically suited to provide low levels of activity for long period of time. These muscles are physiologically postural muscles, being rich in type I fibers, which uncharacteristically have larger diameters than the type II fibers. Although trunk flexor and extensor muscles are physiologically postural muscles area suggests that, they are active throughout most activities, including sitting, standing, lifting or rolling over in bed. ${ }^{1}$

Three factors are essential for the contraction of skeletal muscle: Strength of the muscle, Power of the muscle and Endurance of the muscle. Muscular endurance is defined as 'The ability of a muscle group to execute repeated contractions over a period of time sufficient to cause muscular fatigue, or to maintain a specific percentage of maximum voluntary contraction for a prolonged period of time'. ${ }^{2}$ Lack of endurance of the trunk muscles is an important factor in low back pain (LBP) $)^{3}$. One study states that the overall prevalence of LBP among the students over the past one year was $47.5 \% \quad(n=76)$ with a prevalence of $32.5 \%$ at the time of data collection. Prevalence among males and females was $45.3 \%$ and $50 \%$, respectively. ${ }^{4}$ 
A 25 year prospective study shows that the Young adults who experienced LBP at the age of 14 years had an increased incidence 25 years later compared with those who did not experience LBP at age 14 years. Therefore, preventing and avoiding LBP during early adolescence can prevent LBP progression, and thus, can decrease the associated morbidities ${ }^{5}$.

There are simple tests which can be done to examine the endurance of the low back extensors, abdominal muscles, gluteus maximus and quadriceps for example Static back endurance test (SBET), Repetitive arch-up test (RAUT), Repetitive squat test
(RST), Repetitive sit-up test and side bridge test. The aim of the current study is to evaluate the endurance of trunk extensor group of muscles among college going young adolescents.

In this study we have used Dynamic method of testing 'Repetitive arch-up test' (RAUT) to evaluate the endurance of back extensor muscle. It has correlated better with changes in person's activities of daily living. It has also been suggested that this test may be appropriate to use in person's with the activity or work intolerances like standing, walking, sitting, lifting and balancing.

\section{METHODOLOGY}

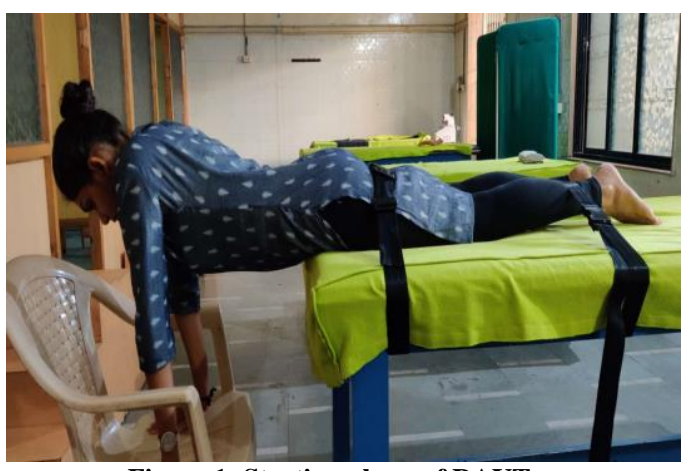

Figure 1: Starting phase of RAUT

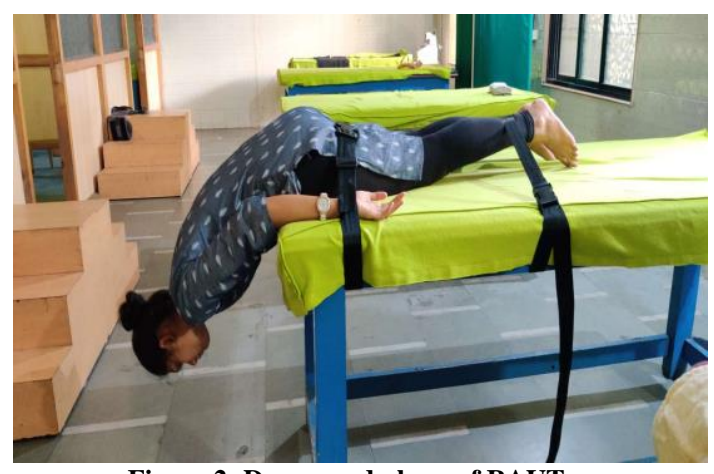

Figure 2: Downward phase of RAUT

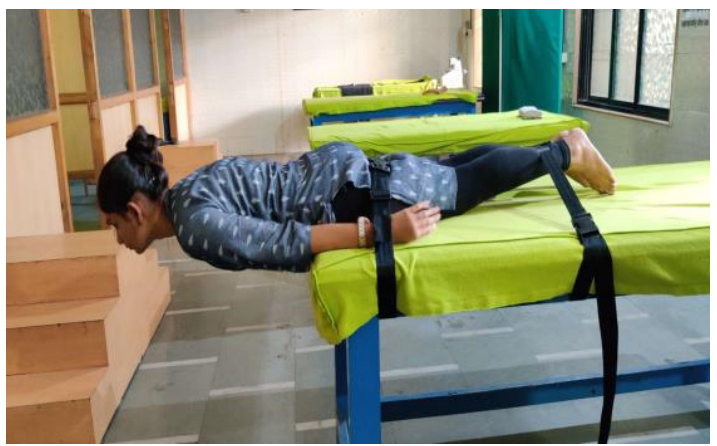

Figure 3 : Horizontal phase of RAUT

In the current study, the participants were enrolled by convenience sampling of students from one college. The data collected includes demographic data such as Name, Age, Sex, Contact information. Clinical data includes height, weight and BMI. In order to sign up for participation, all participants signed and returned a written consent form. Total 30 participants were included using inclusion and exclusion criteria. Instructions were given for how to perform the test. During the test, the participant lay in a prone position on the plinth with arms positioned along the sides. The iliac crest was positioned at the edge of the plinth. The lower body was fixed to the plinth by two non-elastic straps located around the pelvis and ankles (image:1). With the arms held along the sides touching the body, the subject was asked to flex the upper trunk downward to $45^{\circ}$ as indicated by a board (image:2). The participant then raised the upper trunk upwards to the horizontal position followed by returning 
Krupal Modi et.al. Evaluation of dynamic endurance of back extensors in asymptomatic college girls: an observational cross sectional study

back downward to $45^{\circ}$ to complete a cycle (image:3). The repetition rate was one repetition per two to three seconds. The movement was repeated as many times as possible at a constant pace synchronous to a count. Once the movement becomes jerky or nonsynchronous, or did not reach the horizontal level, the subject was encouraged once to immediately correct the motion again. The test was terminated once the participant could not go with the motion or reported fatigue or exhaustion. Do not allow the subject to hyperextend during the test. The number of repetitions is recorded. A maximum of 50 repetitions is allowed. ${ }^{6}$

\section{STATISTICAL ANALYSIS \& RESULT}

For this observational study, a statistical analysis was processed using the Statistics in the Microsoft Office Excel (2007). Means and standard deviations (SD) were calculated using the AVERAGE and STDEV for the age, BMI and Repetitive Arch Up Test as shown in Table no 1.

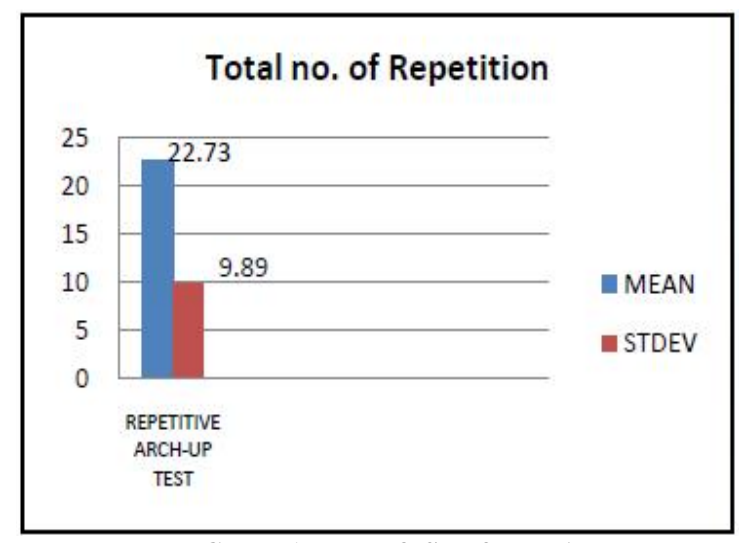

Graph 1: Mean \& SD of the RAUT

\section{DISCUSSION}

A study done in 2018 says that the overall prevalence of LBP among university students was $74.6 \%$. Students with prolonged sitting more than 3 hour in a day reported experience LBP with $79 \%$ while students with prolonged sitting less than 3 hour in a day experience LBP with $63.9 \% .^{7}$ Thus, the aim of the present study was to check the endurance of trunk extensor group of muscles in 19-23 years old female physiotherapy students, to determine the value of lower extensor muscle endurance
Table 1: Mean \& SD of age, BMI and Repetitive arch up test of 30 participants

\begin{tabular}{|l|l|}
\hline BASELINE DATA & Mean \pm SD \\
\hline AGE & $20 \pm 0.83$ years \\
\hline BMI & $21.792 \pm 4.5 \mathrm{~kg} / \mathrm{m} 2$ \\
\hline REPETITIVE ARCH UP TEST & $22.73 \pm 9.896$ \\
\hline
\end{tabular}

The Mean of Repetitive Arch Up Test $=$ Total counts by all individuals $/$ total sample size; 682/30=22.733 (graph: 1). Moreover, the participants into the study were divided according to their performance and categorized into 5 groups. In this study, $10 \%$ females performed 1 to 10 repetitions, $40 \%$ females performed 11 to 20 repetitions, $26.67 \%$ females performed 21 to 30 repetitions, $16.67 \%$ females performed 31 to 40 repetitions and $6.67 \%$ females performed 41 to 50 repetitions (graph: 2). Normative value for RAUT in this age group shows reduced back extensors dynamic endurance in undergraduate physiotherapy female students aged 19 years to 23 years as only few students were able to perform repetitive above 40 times.

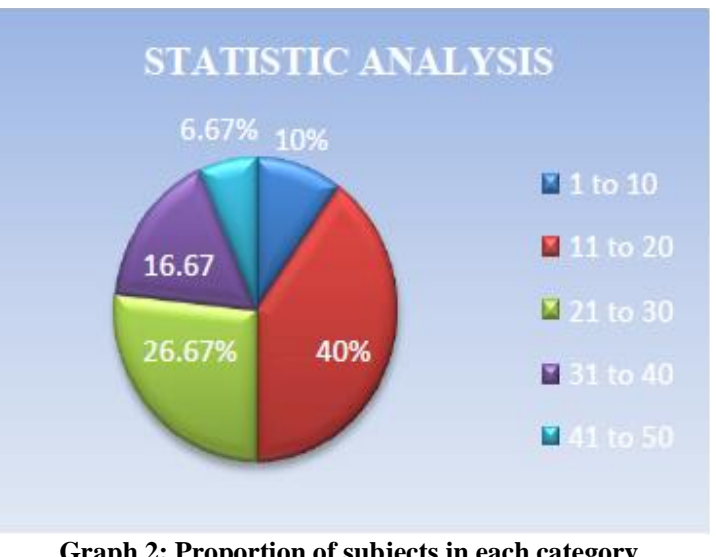

which can help in determining and preventing future low back pain. In this study, the results showed that there was significant reduction in the endurance of trunk extensors muscles in undergraduate physiotherapy students attending lectures for more than 8 hours/day, 6 days/week.

Endurance in muscles is necessary to maintain postural control. Greater type of type II fibres is found in all back muscles, which is reflective of their postural and stabilization function. Sustained postures require continual, small adaptations in the 
Krupal Modi et.al. Evaluation of dynamic endurance of back extensors in asymptomatic college girls: an observational cross sectional study

stabilizing muscles to support the trunk against fluctuating forces. Large repetitive motions also require muscles to respond so as to control the activity. In either case, as the muscles fatigue, the mechanics of performance change and the load is shifted to the inert tissue supporting the spine at the end ranges. With poor muscular support and sustained load on the inert supporting tissues, creep and distention occur, causing mechanical stress. In addition, injuries occur more frequently after a lot of repetitive activity or long periods of work and play when there is muscle fatigue. ${ }^{6}$ Inactivity has been shown to change muscle fiber composition and may be one reason for decreased function in patients with low back pain.

Environmental risk factors have been associated with the development of low back pain in students. Because of the significant amount of time students spend in their college environment, risk factors need to be identified in this environment. It may be due to inappropriate chairs or in the classes, some students sat with their side facing the teacher and some students sat with their backs as well as physical and psychological stresses that a student faces. Study done by Ganeshan S (2017) ${ }^{8}$ indicates following factors were associated with LBP in young adults: marital status, previous history of spine problems, strenuous exercise, job satisfaction, monotony, stress, daily number of studying hours, and family history of spine problems $(\mathrm{p}<0.05)$. However, age, sex, smoking, alcoholism, coffee intake, mode and duration of travel, diet, frequency of weightlifting, wearing heels, studying posture, and frequency and type of sports activities were not associated with LBP. Thus, to assess and strengthen the back muscles become extremely important in this population.

\section{CONCLUSION}

This observational cross-sectional study concludes that, the value of Repetitive Arch Up Test in 30 asymptomatic college girls is markedly reduced. The study of the decisive factors of low back pain is important to identify students at risk, as well as to develop efficient primary prevention programs.

\section{Acknowledgement: None}

\section{Conflict of Interest: None}

\section{Source of Funding: None}

\section{Ethical Approval: Approved}

\section{REFERENCES}

1. Kjær IG, Torstveit MK, Kolle E, Hansen $\mathrm{BH}$, Anderssen SA. Normative values for musculoskeletal- and neuromotor fitness in apparently healthy Norwegian adults and the association with obesity: a crosssectional study. BMC Sports Sci Med Rehabil. 2016 Nov 18;8:37. doi: 10.1186/s 13102-016-0059-4. PMID: 27891234; PMCID: PMC5116214.

2. Charles LD. Chapter 4 Health-related physical fitness testing and interpretation. In: Riebe D, Ehrman JK, Liguori G, Magal $\mathrm{M}$, editors. ACSM's guidelines for exercise testing and prescription 10th ed. Philadelphia: Wolters Kluwer; 2018. pp. 101-2.0

3. Nies N, Sinnott PL. Variations in balance and body sway in middle-aged adults. Subjects with healthy backs compared with subjects with low-back dysfunction. Spine (Phila Pa 1976). 1991 Mar;16(3):325-30. doi: 10.1097/00007632-199103000-00012. PMID: 1827539.

4. Aggarwal N, Anand T, Kishore J, Ingle GK. Low back pain and associated risk factors among undergraduate students of a medical college in Delhi. Educ Health 2013;26:1038

5. Harreby M, Neergaard K, Hesselsoe G, Kjer $\mathrm{J}$. Are radiologic changes in the thoracic and lumbar spine of adolescents risk factors for low back pain in adults? A 25-year prospective cohort study of 640 school children. Spine (Phila Pa 1976) 1995; 20 : 2298-2302.

6. H. Alaranta, "Strength and endurance testing," in The Clinical Application of Outcomes Assessment, S. G. Yeomans, Ed., 
Krupal Modi et.al. Evaluation of dynamic endurance of back extensors in asymptomatic college girls: an observational cross sectional study

pp. 158-162, Appleton \& Lange, Stamford, Calif, USA, 2000.

7. Lucky Anggiat, Wan Hazmy Che Hon, Siti Nur Baait. The Incidence Of Low Back Pain Among University Students. Jurnal Pro-Life, Volume 5, Nomor 3, November 2018

8. Ganesan S, Acharya AS, Chauhan R, Acharya S. Prevalence and Risk Factors for Low Back Pain in 1,355 Young Adults: A Cross-Sectional Study. Asian Spine J. 2017;
11(4):610-617. doi:10.4184/asj.2017.11.4. 610

How to cite this article: Modi K, Ray M. Evaluation of dynamic endurance of back extensors in asymptomatic college girls: an observational cross sectional study. International Journal of Science \& Healthcare Research. 2022; 7(1): 49-53. DOI: https:// doi.org/10.52403/ijshr.20220110 